\title{
Abiotic resource depletion potentials (ADPs) for elements revisited-updating ultimate reserve estimates and introducing time series for production data
}

\author{
Lauran van Oers ${ }^{1}$ (D) Jeroen B. Guinée ${ }^{1} \cdot$ Reinout Heijungs ${ }^{1,2}$ \\ Received: 18 February 2019 / Accepted: 30 August 2019 / Published online: 16 October 2019 \\ (C) The Author(s) 2019, corrected publication 2019
}

\begin{abstract}
Purpose In 1995, the original method for assessing the impact category abiotic resource depletion using abiotic depletion potentials (ADPs) was published. The ADP of a resource was defined as the ratio of the annual production and the square of the ultimate (crustal content based) reserve for the resource divided by the same ratio for a reference resource (antimony ( $\mathrm{Sb}$ )). In 2002, ADPs were updated based on the most recent USGS annual production data. In addition, the impact category was sub-divided into two categories, using two sets of ADPs: the ADP for fossil fuels and the ADP for elements; in this article, we focus on the ADP for elements. Since then, ADP values have not been updated anymore despite the availability of updates of annual production data and also updates of crustal content data that constitute the basis of the ultimate reserves. Moreover, it was known that the coverage of elements by ADPs was incomplete. These three aspects together can affect relative ranking of abiotic resources based on the ADP. Furthermore, dealing with annually changing production data might have to be revisited by proposing new calculation procedures. Finally, category totals to calculate normalized indicator results have to be updated as well, because incomplete coverage of elements can lead to biased results.

Methods We used updated reserve estimates and time series of production data from authoritative sources to calculate ADPs for different years. We also explored the use of several variations: moving averages and cumulative production data. We analyzed the patterns in ADP over time and the contribution by different elements in the category total. Furthermore, two case studies are carried out applying two different normalization reference areas (the EU 27 as normalization reference area and the world) for 2010.

Results and discussion We present the results of the data updates and improved coverage. On top of this, new calculation procedures are proposed for ADPs, dealing with the annually changing production data. The case studies show that the improvements of data and calculation procedures will change the normalized indicator results of many case studies considerably, making ADP less sensitive for fluctuating production data in the future.

Conclusions The update of ultimate reserve and production data and the revision of calculation procedures of ADPs and category totals have resulted in an improved, up-to-date, and more complete set of ADPs and a category total that better reflects the total resource depletion magnitude than before. An ADP based on the cumulative production overall years is most in line with the intent of the original ADP method. We further recommend to only use category totals based on production data for the same year as is used for the other (emission-based) impact categories.
\end{abstract}

Keywords Abiotic resource depletion · ADP · LCA · LCIA · Resource use

Responsible editor: Yi Yang

Electronic supplementary material The online version of this article (https://doi.org/10.1007/s11367-019-01683-x) contains supplementary material, which is available to authorized users.

Lauran van Oers oers@cml.leidenuniv.nl

1 Institute of Environmental Sciences (CML), Department of Industrial Ecology, Leiden University, Einsteinweg 2, 2333 CC Leiden, The Netherlands
2 Department of Econometrics and Operations Research, Vrije Universiteit Amsterdam, De Boelelaan 1105, 1081 HV Amsterdam, The Netherlands 


\section{Introduction}

Abiotic resource depletion in life cycle assessment (LCA), also known as impact assessment of abiotic resource use, is heavily debated. Reasons for this include the lack of an international platform (IPCC, 2018) defining best practice, different perspectives on what actually is the problem of abiotic resource use (Drielsma et al. 2016; Schulze and Guinée 2018), and consequently, there is no "scientifically" correct method (Guinée and Heijungs 1995; p.923). Despite harmonization efforts by the UNEP-SETAC Task Force on natural resources (Sonderegger et al. 2017), the debate on how to assess abiotic resource use in life cycle impact assessment (LCIA) will most likely continue.

This article focuses on one method for impact assessment that has been widely used so far as part of, for example, the Environmental Product Declaration (EPD) (EPD International 2017), Product Environmental Footprint Category Rules (PEFCRs) (European Commission 2017), and the pilot-PEF (European Commission 2013): the Abiotic resource Depletion Potential (ADP). Since ADPs consider "the scarcity of the resource and hence the limitations in its availability to current and future generations [as] the key concern for this impact category" (Hauschild et al. 2013), characterization factors for abiotic resource depletion are vulnerable to temporal changes in production and reserves.

Although the UNEP-SETAC Task Force also recommends the ADP, particularly for quantifying the relative contribution of a product system to the depletion of mineral resources, they also criticized the ADP for only considering the extraction and stocks of mineral resources and neglecting anthropogenic stocks and dissipation rates. This article only focuses on updating the data and increasing the resource coverage of the present method only, without substantial changes in the characterization model. In another project (Schulze and Guinée 2018), we address the Task Force's criticisms and propose new approaches including consideration of anthropogenic stocks and dissipation.

The ADP-method, originally developed by Guinée and Heijungs (1995), is based on a scarcity indicator that combines production and reserve of individual elements:

- production: the world annual production $(P$, in $\mathrm{kg} /$ year) of the element

- reserve: the estimated ultimate global reserve ( $R$, in $\mathrm{kg})$ of the element

The $R$ could also be measured differently, e.g., as the reserve defined by the US Geological Survey (USGS), i.e., that part of the reserve base which could be economically extracted or produced at the time of determination (US Geological Survey 2018). However, the disadvantage of the "reserve" as defined by USGS is that estimating the size of the reserve involves a variety of technical and economic considerations not directly related to the environmental problem of resource depletion. Reserve estimates are relatively certain as they are based on present practice, but they are also highly unstable and continuously change over time (van Oers and Guinée 2016). Using the ultimate reserve based on the crustal content gives a better and more robust indicator of reserve. The idea is that in a long-term sustainability perspective, such ultimate reserves provide a better metric of what the Earth offers us than a technology and market-dependent metric. ${ }^{1}$ Over the years, there has been little change of these ultimate reserve data. This is of course different for the production $P$, which is following trends in society and technology. For instance, many rare-earth elements, such as neodymium and dysprosium, have displayed a steep increase in production, due to new areas of applications. One might be tempted to have such apparent changes in importance reflected in the ADP. That would then not only require a regular update of these ADPs but it would also require reconsidering the original intent of the ADP, which was to assess long-term effects rather than short-term (see section 4).

In 2002, ADPs were updated (van Oers et al. 2002) based on the most recent USGS annual production data. In addition, the ADP was sub-divided into two categories and two sets of ADPs: the ADP for fossil fuels and the ADP for elements. Since then, the ADPs for elements have not changed despite ongoing annual updates of production data and also a few updates of crustal content data that constitute the basis of the ultimate reserves. Moreover, it was known that the coverage of elements by ADPs was incomplete. These shortcomings can potentially affect relative ranking of elementary resources and also normalized indicator results for ADP-based abiotic resource depletion, which is a problem well-known of other (e.g., the toxicity-related) impact categories (Heijungs et al. 2007; Prado et al. 2016).

In this article, we focus on the list of ADPs for elements. We aim to update the $P$ and $R$ data that are the basis of the ADP, analyze the changes over time that can be found in the ADPs due to annually changing $P$ values, and discuss the disadvantages of such volatile characterization factors, along with several proposals to deal with it. Finally, we propose a more robust updating procedure of the data behind the ADP and its category total for the current PEF guidance (version 6.3 from May 2018 at the time of writing) (European Commisison 2017).

We take the ADP method as a starting point without discussing possible modifications such as including technosphere stocks as proposed by Schneider et al. (2015) or other potential methods. Of course, there are method debates

\footnotetext{
${ }^{1}$ This implicitly assumes that the ratio between the ultimately extractable reserve and the ultimate reserve is equal for all resource types. In reality, this will not be the case, because the concentration-presence distribution will most likely be different for each resource (van Oers and Guinée 2016).
} 
ongoing (Sonderegger et al. 2017; Schulze and Guinée 2018) adopting other principles for assessing the impacts of resource use, but as mentioned above, discussing these developments was not part of this work. In section 2, we describe the data sources and calculation procedures. Section 3 presents the results, including an analysis of the results. Section 4 discusses these results. All data and results can be found in the Electronic Supplementary Material (ESM).

\section{Methods}

\subsection{Definitions, terms, and symbols}

Guinée and Heijungs (1995) defined the ADP for resource $i$ as follows:

$A D P_{\mathrm{i}}=\frac{\frac{P_{i}}{R_{i}^{2}}}{\frac{P_{r e f}}{R_{\text {ref }}^{2}}}=\frac{P_{i} R_{\text {ref }}^{2}}{R_{i}^{2} P_{\text {ref }}}$

Here, $P_{i}$ is the world annual production ( $\left.\mathrm{kg} / \mathrm{year}\right)$ of resource $i$, and $R_{i}$ its ultimate reserve (kg). The ADP of resource $i$ is the ratio for resource $i$ divided by that of a reference resource, indicated as ref. Usually, this is antimony ( $\mathrm{Sb}$ ), but the precise choice is irrelevant in the final results, comparable with the choice between kilogram and pound.

Adopting the ADP as characterization factor, the corresponding category indicator result, here referred to as $\mathrm{AD}$, is calculated as follows:

$A D=\sum_{i} A D \mathrm{P}_{i} \times m_{i}$

where $m_{i}$ is a product's use of resource (element) $i(\mathrm{~kg})$ and the summation is understood to run over all elements covered.

When a normalization step is part of the LCIA phase, a category total can be found for the impact category abiotic depletion by calculating the category indicator result for a specified reference region and time period. The elementary flows (i.e., resource extractions from nature) for a specified reference region and time period are indicated by $M_{i}$ and are usually measured in per-time units, such as $\mathrm{kg} /$ year. The category total for abiotic resource depletion (TAD) is then found by:

$T A D=\sum_{i} A D P_{i} \times M_{i}$

and the normalized category indicator result for abiotic resource depletion (NAD) as:

$N A D=\frac{A D}{T A D}=\frac{\sum_{i} \frac{P_{i}}{R_{i}^{2}} \times m_{i}}{\sum_{i} \frac{P_{i}}{R_{i}^{2}} \times M_{i}}$
When $\mathrm{AD}$ is in the unit kg Sb-equivalent and TAD is in the unit kg Sb-equivalent/year, NAD is in the unit year; the mathematics demonstrate that it is independent of the choice of the reference substance (see Appendix A - ESM). A special situation is when the resource's global production $(P)$ that is used in constructing the ADP and the elementary flows $(M)$ that are used for the category total coincides, that is, when they are for the same region (world) and year. In that case, $M_{i}=P_{i}$ and

$$
T A D=\sum_{i} A D P_{i} \times P_{i}=\frac{R_{r e f}^{2}}{P_{\text {ref }}} \sum_{i}\left(\frac{P_{i}}{R_{i}}\right)^{2}
$$

and

$$
N A D=\frac{\sum_{i} \frac{P_{i}}{R_{i}^{2}} \times m_{i}}{\sum_{i}\left(\frac{P_{i}}{R_{i}}\right)^{2}}
$$

Despite this possible identification of $M_{i}$ with $P_{i}$, we will keep the symbols separate, as it might be useful to choose different regions or time periods for the production in calculating the $\mathrm{ADP}$ and the category total. As will be shown later in this article, the ADP might be based on the world resource production $(P)$ in a specific year $t$, or an average or cumulative production over a period, while the world resource use that is used to calculate the category total for abiotic resource depletion might be based on a specific recent year $y$.

Because annual production differs per year, ADPs also differ, and so do the category indicator results. When relevant, we will add an extra subscript $t$ to indicate the year, creating $P_{i, t}, A D P_{i, t}$, $A D_{t}$, etc. Table 1 summarizes the terminology and symbols.

\subsection{Production data}

For updating production data, the annual reporting by USGS (US Geological Survey 2018) and BGS (British Geological Survey 2018) was utilized. Production data were downloaded for the time series 1900-2015 from the USGS website and for the period 1970-2016 from the BGS website. For more recent years, world production data reported by USGS refer to world mine production. Some historic data refer to smelter production and may thus include secondary resources. BGS provides production data for different stages of production and distinguishes between "metal, mine", "metal, refined", and "metal, smelter" for most metals. As the ADP refers to primary production, we used the production reported under "metal, mine" for our updated work. This should imply that we included only primary production data excluding secondary (recycled) material. $^{2}$

\footnotetext{
$\overline{2}$ However, in the original reports from USGS and BGS, it is indicated that for some resources in some years and/or some countries, the primary production data might include also some secondary production.
} 
Table 1 Overview of main terms and symbols adopted for describing ADP-based characterization and normalization

\begin{tabular}{|c|c|c|c|c|c|}
\hline \multirow[b]{2}{*}{ Name } & \multicolumn{2}{|c|}{ In general* } & \multicolumn{3}{|c|}{ For abiotic depletion } \\
\hline & Symbol & Source & Symbol & Unit** & Source \\
\hline Elementary flow & $m_{i}$ & Calculated in LCI & $m_{i}$ & $\mathrm{Kg}$ & $\begin{array}{l}\text { Extraction, calculated } \\
\text { in LCI }\end{array}$ \\
\hline Characterization factor & $C F_{j, i}$ & $\begin{array}{l}\text { Derived from } \\
\text { characterization model }\end{array}$ & $\mathrm{ADP}_{i}$ & $\mathrm{~kg} / \mathrm{kg}$ & $=P_{i} / R_{i}^{2} / P_{\text {ref }} / R_{\text {ref }}^{2}$ \\
\hline Category indicator result & $C_{j}$ & $=\sum_{i} \mathrm{CF}_{j, i} \times m_{i}$ & $\mathrm{AD}$ & $\mathrm{kg}$ & $=\sum_{i} \mathrm{ADP}_{i} \times m_{i}$ \\
\hline Normalized category indicator result & $N C_{j}$ & $=\frac{C_{j}}{T_{j}}$ & NAD & year & $=\frac{\mathrm{AD}}{\mathrm{TAD}}$ \\
\hline World annual emission/extraction & $M_{i}$ & from global inventory & $P_{i}$ & $\mathrm{~kg} /$ year & Extraction from USGS \\
\hline Ultimate reserve of resource $i$ & na & na & $R_{i}$ & $\mathrm{~kg}$ & $\mathrm{~kg}$ \\
\hline World annual use of resource $i$ & na & na & $M_{i}$ & $\mathrm{~kg} /$ year & $\mathrm{kg} /$ year \\
\hline Category total & $T_{j}$ & $=\sum_{i} \mathrm{CF}_{j, i} \times M_{i}$ & TAD & $\mathrm{kg} /$ year & $=\sum_{i} \mathrm{ADP}_{i} \times M_{i}$ \\
\hline Normalized indicator result & $N_{j}$ & $=\frac{C_{j}}{T_{j}}$ & NAD & year & $=\frac{\mathrm{AD}}{\mathrm{TAD}}$ \\
\hline
\end{tabular}

*Symbols only used in Appendix 1 and 2

**These units are the most common ones, but kg may in certain cases be MJ or DALY, etc

USGS and BGS data for the same resource may differ for many reasons (like differences in units (e.g., tonnes ore versus tonnes element content) or institutions reporting to the geological surveys or completeness of the minerals for which an inventory is made). A thorough analysis of the differences in reported element extractions was beyond the scope of this article. In this article, USGS production data have been adopted as baseline data for the calculation of ADPs. The main reason for this is that USGS data are provided mostly in tons of element (in contrast to BGS data), which is the entry needed for the calculation of ADPs. For resources where USGS lacks entries (like for aggregates and clays), BGS data were used. Data on platinum group of metals (PGM) and titanium minerals were also retrieved from BGS because these data enabled breakdown into different PGM elements and titanium ores. Breaking down aggregate data on rare-earth minerals is based on Adibi et al. (2018). For some elements data are not reported by either USGS or BGS, such as cerium, hafnium, ruthenium, and scandium. Production data for these elements were taken from an EU report (Deloitte Sustainability et al. 2017). This report provides average data for these elements over the period 2010-2014. It has been assumed that these elements have also been used in the same amount in previous periods (1970-2009).

USGS and BGS also report production data for some minerals that are extracted to be used as such. This concerns minerals like bentonite, diatomite, and gypsum. In the actual markets, these minerals are considered to be irrelevant for the total primary extraction of metals and elements as such (dedicated extractions). However, by extracting these minerals, the elements are also extracted (non-dedicated extractions) from the earth crust. In this way, the extractions of these minerals also contribute to the total production of element $i\left(P_{i}\right)$ in the ADP equation. The production data for these minerals were therefore also taken into account in the estimation of the $P_{i}$. An average composition of these minerals in terms of elements was used for converting them into elementary compositions (see ESM1: sheet "minerals to elements matrix").

\subsection{Reserves data}

For updating the ultimate reserves, we need basic earth data and data on crustal content. Basic earth data on the volume and mass of the earth, ocean, and atmosphere were taken from Harte (1988). For the calculation of the ultimate reserves, the crustal content concentrations as compiled by Rudnick and Gao (2014) were used. Their report is considered the standard in geological sciences and is accepted by industry as the reference for average crustal concentrations (Drielsma et al. 2016). Lacking data were supplemented by estimations from Lide (1990). The data on the thickness of the different layers were taken from Rudnick and Gao (2014). Based on this, the average depth of upper earth crust was assumed to be $12 \mathrm{~km}$. At present, the deepest mines are at approximately $4-\mathrm{km}$ depth.

\subsection{Calculation procedures}

Because production data show large fluctuations over time, the ADPs will fluctuate over time. We developed three different strategies for dealing with this time issue when calculating ADPs:

- Calculate a time series of ADPs with that year's production data; 
- Calculate a time series of ADPs on the basis of a moving average of the production;

- Calculate a time series of ADPs on the basis of the cumulative production up to that year.

Below, we present the detailed mathematical procedures for each.

A time series of ADPs on the basis of that year's production is found through

$A D P_{i, t}=\frac{P_{i, t} R_{r e f}^{2}}{R_{i}^{2} P_{r e f, t}}$

A moving average uses the production of that year and a number of previous years. If the number of years used in the averaging is indicated by $m$, we use

$\bar{P}_{i, t}=\frac{P_{i, t}+P_{i, t-1}+\ldots+P_{i, t-m+1}}{m}=\frac{1}{m} \sum_{k=t-m+1}^{t} P_{i, k}$

For the first few years, we take a shorter time span because the time series does not provide the necessary data for the full calculation. With this, we use

$\overline{A D P}_{i, t}=\frac{\bar{P}_{i, t} R_{r e f}^{2}}{R_{i}^{2} \bar{P}_{r e f, t}}$

The idea behind a cumulative ADP is that the more of a resource has been taken out, the more serious the problem becomes. The cumulative production up to a year is given by:

$\widetilde{P}_{i, t}=P_{i, t}+P_{i, t-1}+\ldots=\sum_{k=1}^{t} P_{i, k}$

The physical unit of $P$ is not $\mathrm{kg} /$ year, but $\mathrm{kg}$. The corresponding cumulative ADP is found as follows:

$\widetilde{\mathrm{ADP}}_{i, t}=\frac{\widetilde{P}_{i, t} R_{r e f}^{2}}{R_{i}^{2} \widetilde{P}_{r e f, t}}$

For purposes of normalization, category totals were developed in a similar way:

- a category total per year on the basis of that year's production: $T A D_{t}=\sum_{i} A D P_{i, t} \times P_{i, t}$;

- a category total per year on the basis of a moving average production: $\overline{T A D}_{t}=\sum_{i} \overline{A D P}_{i, t} \times P_{i, t}$;

- a category total per year on the basis of a cumulative production: $\widetilde{T A D}_{t}=\sum_{i} \widetilde{A D P}_{i, t} \times P_{i, t}$.

Note that theoretically, the $t$ in ADP and $P$ can reflect different years and should therefore have different symbols. However, for ease of notation, the same $t$ has been adopted above. Whenever relevant, we will indicate in the captions of tables and graphs which $t$ has been taken for the ADP and which one has been adopted for the $P$.

Finally, for purposes of comparison with the existing practice, the 1999 ADPs as defined in Guinée et al. (2002) and compiled in the impact assessment spreadsheet CML-IA 2002 (CML-IE, 2018) were used. This set of ADPs from the CMLIA spreadsheet is based on yearly extractions of elements as compiled by USGS (US Geological Survey 2018). The extraction rates of elements refer to the year 1999. The calculation of the crustal content is based on Clarke and Washington (1924), Guinée and Heijungs (1995), and van Oers et al. (2002).

\section{Results}

Below, the results of the calculation of characterization factors and category totals for abiotic resource depletion of elements, according to three different strategies for dealing with time, are presented and analyzed. Based on the updates of $P$ and $R$ as described above, we were able to calculate new ADPs for 76 out of the total of 109 elements of the periodic table over the time period 1970-2015. The previous set of characterization factors for abiotic resource depletion contained ADPs for 48 elements. All results are also included in the spreadsheet that is part of the ESM (ESM1) and we refer to the different sheets of this spreadsheet for calculation details when presenting and analyzing the results below.

\subsection{ADPs}

The first strategy is to calculate a time series of ADPs with that year's production data. Full results can be found in ESM1, sheet a\&g (ADPs); columns E-AX. It appears that the ADPs of individual elements differ in many orders of magnitude, for instance for aluminum, it is around $10^{-8} \mathrm{~kg}$ antimony-equivalent $/ \mathrm{kg}$, for chromium, it is around $10^{-3}$, and for gold, it is around $10^{3}$. To give an idea of the pattern over time, Fig. 1 shows the time series of a few high-value ADPs (ADPs for year $t$ based on that year's production data). We clearly see that there is quite some variation of the ADP values over time, but also that there is quite some consistency, e.g., gold is always higher than tellurium and palladium, and almost always higher than platinum. We also see that there are missing values (shown in the graph as zero), due to either missing production or reserve data, for the first few years for rhenium and palladium. The yearly variations of most ADPs and calculating ADPs with the most recent production data imply that ADPs should basically be updated every year, which may not be very practical and attractive for many applications, including policy setting or frameworks.

The second strategy is to calculate a time series of ADPs on the basis of a moving average of the production. Full results 
Fig. 1 Times series of the eight elements with the largest ADP values (ADPs based on that year's production data)

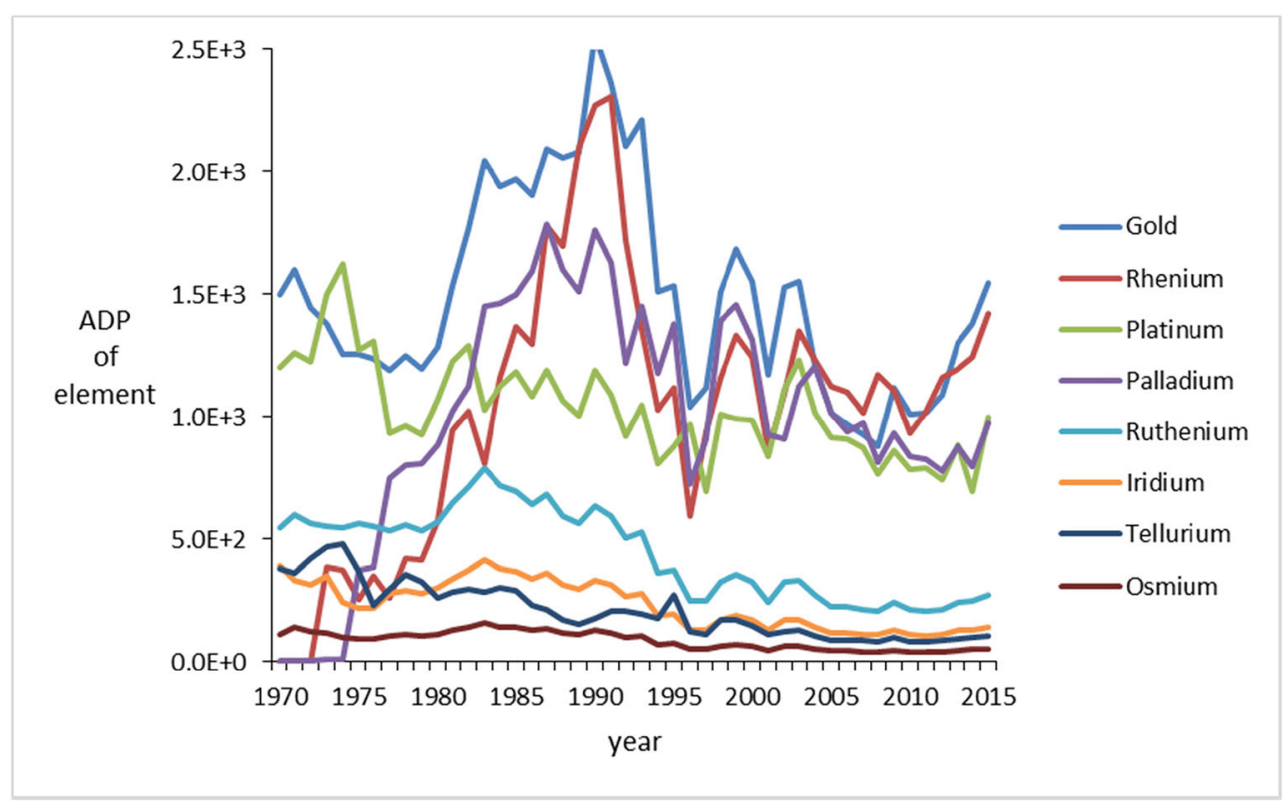

can be found in ESM1, sheet "a\&g (ADPs) recommended ADP \& norm data"; columns BH-DH. Figure 2 shows the effect of averaging over 5 years for the ADP of copper compared with yearly updated ADPs (first strategy). With a moving average over 5 years, we clearly see that the peaks are dampened and that a longer time window leads to smoother and more stable lines. From a practical and policy point of view, stable values are convenient. But of course, they may miss certain information that might be relevant. For instance, in Fig. 2, we see a highly fluctuating annual ADP between 1995 and 2005, which in the 5 years moving average is largely invisible. We could also adopt longer averaging periods, e.g., 20 or 40 years, in which case, the line will almost be flat. That would solve the issue of fluctuating ADPs, but it would also not show any trends (see section 4 ).

The third option is to calculate ADPs on the basis of the cumulative production up to the year of interest. In the definition of the ADP, we see $\frac{P}{R^{2}}$, where the $P$ is quite arbitrarily defined on a per annum basis. In the second strategy, we adopted a 5 years average for the production but we might also have taken a longer or shorter accounting period. While 1 year (first strategy) is the extreme for a shorter period, the extreme for a longer period is by looking at the cumulative production. With this, cumulative ADPs can be calculated. Full results can be found in ESM1, sheet "a\&g (ADPs) recommended ADP \& norm data"; columns GS-IL. We could even correct the reserve $R$ for the cumulative production, deducting every year a part of the remaining reserve (see columns IN-KG). If we do so, we find for most elements no or negligible differences ${ }^{3}$ (see ESM1, tab sheet 'Table 4'), and therefore, the corrected $R$ is excluded from hereon. Table 3 illustrates the differences between the annual ADP, the moving average ADP, and the cumulative ADP for all resources. Figure 2 highlights the case of copper. For an interpretation of the results and recommendations on which ADP type to use, refer to "Discussion".

\subsection{Category total}

Figure 3 presents the results of the category total calculated according to the three alternative strategies.

Similar to the ADPs, we see a strongly fluctuating pattern when the category total is calculated per year adopting the ADP per year (first-strategy ADP). The fluctuations are again flattened out a bit when the category total is calculated per year adopting the ADP based on a moving average (secondstrategy ADP), and results in an even smoother line with an overall upward trend when the category total is calculated per year adopting the ADP based on the cumulative production up to the year of interest (third-strategy ADP). The strong fluctuating pattern raises the question whether it is the result of one or a few resources, or if it is due to an overall underlying cause, such as economic development.

To analyze this, we first study the contribution by different resources in the category total. In doing this, first observe that we use a global reference area and a calendar year as a reference time period. So, for the global annual use $M_{i}$, we take the global extraction $P_{i}$ for 2015 . Because the category total is the result of a sum over all resources,

$T A D=\sum_{i} A D \mathrm{P}_{i} \times P_{i}$
${ }^{3}$ Please note that this is because we have used crustal content as a proxy for the relative distribution of elements in the crust not for the absolute extractable amount. The absolute extractable amount will most likely be much less. 
Fig. 2 ADP by year, moving average of ADP with time windows of 5 years and cumulative ADP, for copper ( $\mathrm{av}=$ average; cum $=$ cumulative)

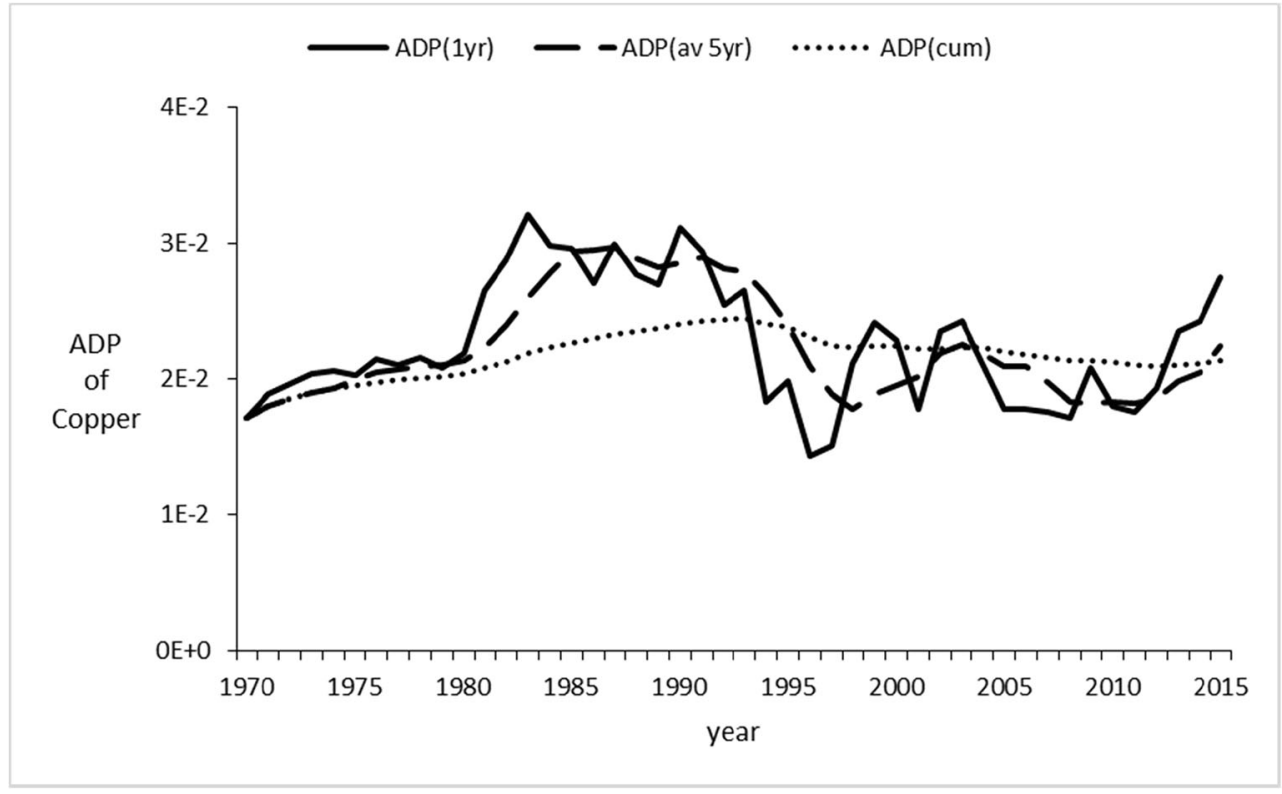

we can study the quantity $\mathrm{TAD}_{i}$, defined by

$T A D_{i}=\frac{A D \mathrm{P}_{i} \times P_{i}}{T A D}$

as the share of resource $i$ in the category total. There appears to be a very uneven distribution here. For barium, for instance, the contribution is less than $0.1 \%$, while it is around $70 \%$ for gold (it varies between 61 and $80 \%$, depending on the year). In Table 2, the top 20 contributions of elements to the category total $\left(\mathrm{TAD}_{2015}\right)$ are presented (adopting first-strategy ADPs and reference year 2015). The total list can be found in ESM1 (sheet "recommended ADP \& norm data" a\&g (norm. data, year 2015)'; columns E-AX).

Just a handful of elements contribute more than 1\%: besides gold, these are antimony, cadmium, chromium (in some years), copper, lead, mercury (in some years), molybdenum, palladium (in some years), platinum, silver, tellurium, and tin (in some years). Figure 4 shows their share pattern over time (adopting first-strategy ADPs).
Fig. 3 Time series of the category total for abiotic resource depletion. Three alternative calculations of the category total are presented: ADP based on yearly production, ADP based on a moving average production, and ADP based on cumulative production up until a specific year. To calculate the yearly category totals, the ADPs are multiplied with the production of 2015

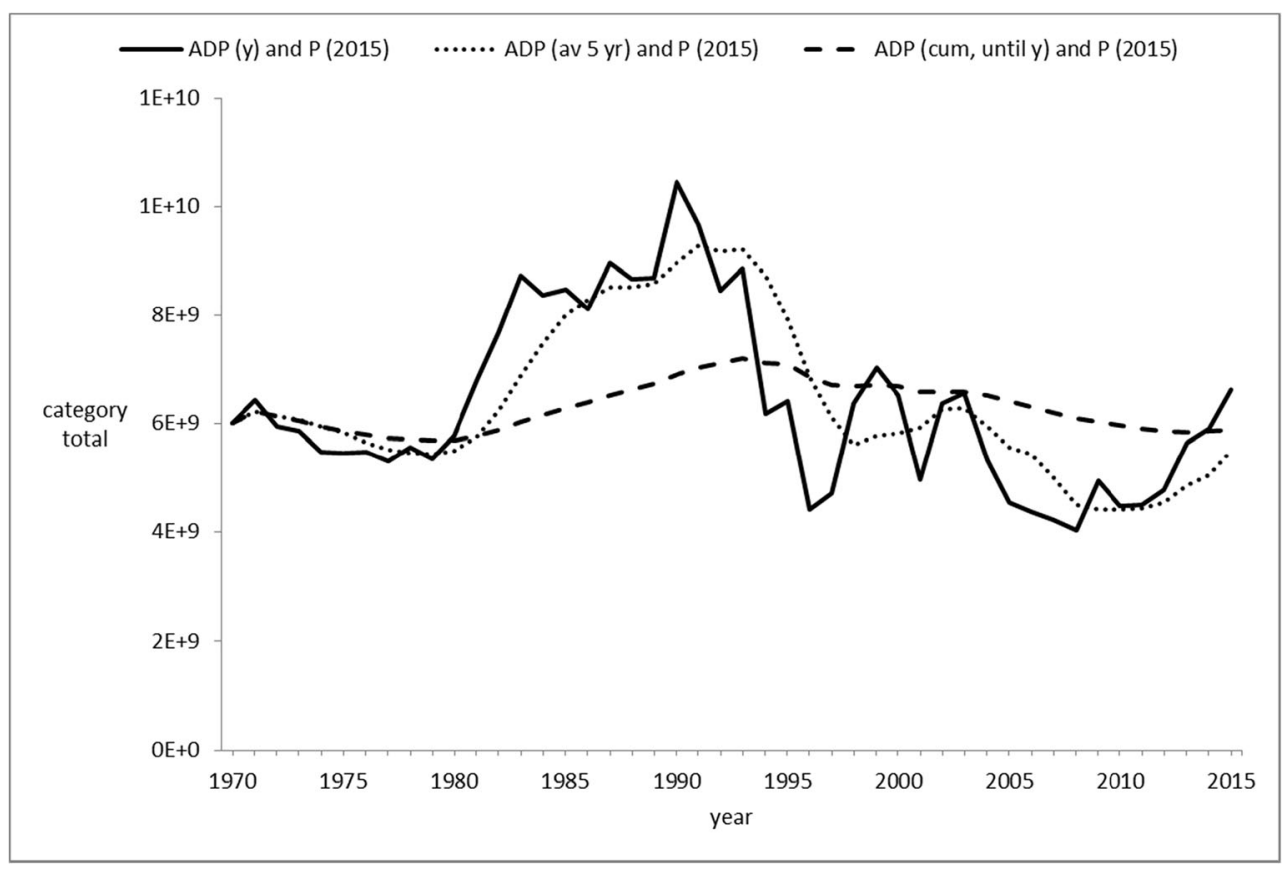


Table 2 Top 20 elements contributing to the category total of abiotic resource depletion of elements (adopting the ADP for 2015)

\begin{tabular}{ll}
\hline Element & $\begin{array}{l}\text { Share in category } \\
\text { total for 2015 (in \%) }\end{array}$ \\
\hline Gold & 72.4 \\
Copper & 7.9 \\
Silver & 3.8 \\
Palladium & 3.5 \\
Platinum & 3.3 \\
Antimony & 2.1 \\
Lead & 1.4 \\
Cadmium & 1.1 \\
Rhenium & 1.1 \\
Molybdenum & 0.8 \\
Zinc & 0.6 \\
Boron & 0.4 \\
Tin & 0.3 \\
Sulfur & 0.3 \\
Chromium & 0.2 \\
Tellurium & 0.2 \\
Bismuth & 0.1 \\
Ruthenium & 0.1 \\
Mercury & 0.1 \\
Phosphorus & $<0.05$ \\
\hline
\end{tabular}

Note that this dominance of the category total by just a few elements is a phenomenon also seen for other impact categories in normalization (Wegener Sleeswijk et al. 2008; Van Oers and Huppes 2001). For example, the category total for global warming is $65 \%$ due to $\mathrm{CO}_{2}$; the ozone depletion category total is $44 \%$ due to $\mathrm{CFC}-12$; the human toxicity category total is $27 \%$ due to chromium; the freshwater ecotoxicity category total is $67 \%$ due to aldicarb etc. (see the "impact assessment" spreadsheet CML-IA (CML-IE). The dominance of the abiotic resource depletion category total by gold is thus not a unique phenomenon within the current state-of-the-art of normalization. Limitations of characterization models and data do of course influence these results, but given the problem definition and ADP-model used, the dominance of the category total result by a few elements is a mathematical fact. Considering the price, demand and reserves of gold, this dominance of gold is also an understandable result given the ADP model.

\subsection{Sensitivity and uncertainty}

Above, we studied the temporal variation of ADPs and their contribution to the category total. In this section, we consider the effect of two choices we made, i.e., the choice of reference substance and the treatment of the variability of the production data as uncertainty.

\subsubsection{Choice of reference substance}

The reference substance for the ADP is by default antimony. In principle, the choice is unimportant and will not affect the relative scores in a comparative analysis and neither will the contribution by different resources change (see Appendix B ESM). But it might be the case that the data of the reference substance antimony itself is variable over time. Indeed, the production of antimony ranges between $4.74 \times 10^{7} \mathrm{~kg} /$ year in 1983 and $1.93 \times 10^{8} \mathrm{~kg} /$ year in 2013 , which is
Fig. 4 Contribution to the category total by the most contributing resources, excluding gold. (Category totals are based on ADPs based on that year's production times the production in a specific year)

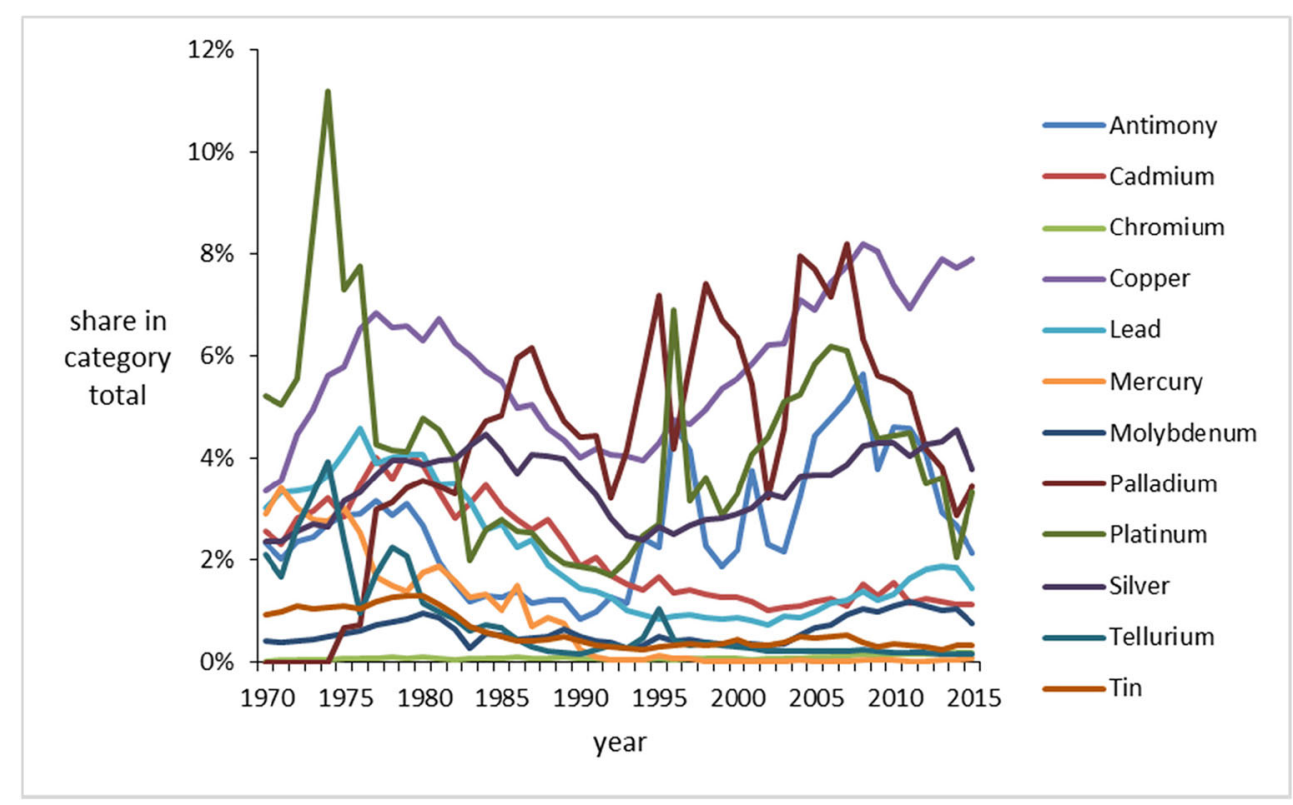


approximately a factor 4 . For tantalum, these extreme values are $6.08 \times 10^{3} \mathrm{~kg} /$ year in 2010 and $1.72 \times 10^{4} \mathrm{~kg} /$ year in 1983 , which is with approximately a factor 3 , the smallest difference. This is not too different from antimony, and we conclude that although the antimony data change over time, the effects are not much larger than when another reference would have been chosen.

\subsubsection{Treating the variability of the production data as an uncertainty}

Next, we address the variability of the production data as an uncertainty and apply the Gaussian theory of error propagation. The idea is that the variance of calculated results can be expressed, as an approximation, in terms of a sum of the variances of the contributing variables. For more details, we here refer to ESM 2. The conclusion from this exercise is that in particular, the variability of the production of gold completely dominates the variability of the category totals. As a consequence, it would be a bad idea to use the resource that has the highest contribution to the category total, i.e., gold, as a reference substance. Although the choice of reference from a mathematical point of view is unimportant, stability over time is a desirable property. In that sense, antinomy is a more suitable reference than gold. In this respect, abiotic resource depletion therefore differs from global warming, for which the most important greenhouse gas, $\mathrm{CO}_{2}$, is the reference. Furthermore, the variability of reserve data seems to be of minor importance to the variability of the category totals.

\section{Discussion}

The aim of this work was to update the data $(R$ and $P$ ) behind the ADP, to revisit its calculation procedure to better deal with the time dependency of $P$ data, and to develop a proposal for a more robust updating procedure of the data behind the ADP and its category total for the current PEF guidance (version 6.3 from May 2018 at the time of writing) (European Commisison 2017).

We discuss the results in the light of the three aims of this study: updating basic $P$ and $R$ data, calculation procedures, and updating procedure. We add to that a discussion on "consistency" since applying ADPs and category totals in practice may raise consistency issues.

\subsection{Basic earth, $P$, and $R$ data}

For the calculation of the ADPs, data are needed and assumptions are made which might lead to different characterization factors and category total for abiotic resource depletion based on the ADP.
Basic earth data are used to calculate the volume and mass of the continental earth crust, like depth, surface area, and density. Together with the concentration of the elements in the continental crust, these data are used to estimate the ultimate reserves. Since - in the end-ADP is a relative expression of the potential contribution of elements to depletion, the relative availability of elements as expressed in $R$ is of importance, and the absolute values of the reserves are of less importance. Consequently, the adopted earth crust's depth, area, and density will not influence the contribution of the elements and thus the value of the ADP as long as within the volume of the compartment (area $\times$ depth), the concentration is considered to be homogeneous. This is most likely not entirely reflecting reality but data on concentrations provided by Rudnick and Gao (2014) are given as average data for the upper earth crust and as such considered homogeneous.

In the present calculation of ADPs, only the continental crust is considered. Mining of the oceanic crust is not foreseen in the near future. Again, expanding the volume of the crust by taking into account the oceanic crust will not affect the ADPs considerably as long as the composition of the oceanic crust is more or less the same as the composition of the continental crust. However, concentrations of elements in the oceanic crust are believed to be very different compared with the continental crust (White and Klein 2014), so if mining of the crust beneath the oceans is considered feasible, oceanic crust could become important.

For the ultimate reserve, crustal content data from Rudnick and Gao (2014) were adopted. Significant changes in crustal content data are not expected, but if they occur, these should lead to further updates of ADPs and category total in future.

Production data are compiled by many different geological surveys, like USGS and BGS. Different geological surveys report sometimes different production data. There are many different reasons why reported production data may differ, such as different principles of the classification of minerals, differently assumed concentrations of elements in ores and minerals, different units (tons ore, tons element, tons compound), and different responses the surveys get from geological surveys, statistical bureaus, and industry. USGS and BGS meet yearly to mutually align their data, at least for some of the most important elements and metals. A yearly mutual tuning of production data for all the elements and minerals by all stakeholders is recommended — not just for the purposes of ADP calculations, but for improvement of all future efforts to model raw material supply.

\subsection{Calculation procedures}

A key challenge addressed in this work has been how to deal with the fact that production data annually fluctuate, resulting in potentially widely fluctuating ADP values and category totals over different years. In addition to just adopting the most recent 
production value for calculating the ADP and category total, we have analyzed two other options for calculating the ADP:

1. Using a moving average (av) production over a number of years;

2. Using the cumulative (cum) production from the start of data availability up to the year of interest.

The differences between the 2 alternative options appear to be small (see Table 3), and they go in different directions for different resources. Table 3 shows individual ADPs for individual elements. The differences between the 3 different calculation procedures for the ADP (i.e., ADP_2015, ADP_2015 (moving average), and ADP_2015 (cumulative)) of a specific element have a maximum variation between 0.2 and 1.8 , and only between 0.7 (rhenium) and 1.5 (tellurium) for the eight highest ADPs (Fig. 1) (see ESM1, Table 3 sorted). The key point in making a choice between the annual ADP, a moving average ADP (1), or a cumulative ADP (2) and between the different time horizons for averaging basically comes down to addressing two questions:

1. Should ADPs reflect trends in economy, technology, demands, etc. or not? For example, the demand for metal products tends to be very income elastic and therefore highly cyclical. This is reflected in more-or-less regular periods of high or low commodity prices, which are readily associated with higher or lower levels of gross national product (Drielsma et al. 2016). A time period of 20 years is more likely to capture more than one of these price/ production cycles and therefore smooth out such shorter-term effects when attempting to characterize a much longer-term effect. On the other hand, a 20 years average is unlikely to capture the short-term rise and fall in demand of new or declining resources, such as the rareearth metals. Whatever choice is preferred, it needs to be made consistently for all resources, so not a 20 years average for resource $X$ and 5 years average for resource $Y$.

2. To what extent should ADPs reflect how problematic society's use of primary natural resources cumulatively is in terms of running out of primary natural resources? ${ }^{4}$ One consistent option here could be to adopt the cumulative production over time for which USGS/BGS have collected production data, correct the crustal contentbased reserve for that cumulative production, and use these for calculating the ADP. This would be quite in line with the way other impact categories are modeled. For

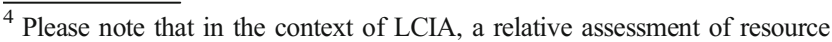
availability is meant. It is important to recognize the limitations of the ADP here. The ADP expresses the relative contribution to resource depletion of a 1$\mathrm{kg}$ extraction from nature of a specific element compared with a similar extraction of antimony. As a consequence, the ADP cannot be used as such for absolute assessments.
}

example, global warming is modeled taking into account all emissions that occurred in the past. Adopting another time horizon, for example, cumulative production over the 20 years (e.g., 1996-2015) seems to make no sense as that would only reflect partially how problematic society's use of primary natural resources so far is. However, in determining the cumulative use of resources by society, we do face a data problem, because reliable production data for most elements does not go back further than a few decades. Please note that this lack of production data might partly be due to historically negligible production compared with today's production levels. Targeted commercial production of some elements did not really commence until the 1970s.

Which option is taken is a normative choice and open for debate which is inextricably linked to the aim of the impact assessment method. If the method should reflect trends, the most suitable option would be to adopt the average production over 5 years (fourth column in Table 3) as longer averaging periods will increasingly flatten out the trends (see Fig. 2). In this case, however, the use of crustal content (ultimate reserves) might no longer be appropriate. If the ADP should reflect how problematic society's use of primary natural resources cumulatively is, the cumulative ADP over time for which we have production data (last column of Table 3 ) is the most appropriate option to adopt, with or without correction of the $R$ for the cumulative production (in practice, there is no difference between the two). Since the latter is in line with the original aim of the ADP method, the cumulative option is recommended here.

\subsection{Update procedure}

Independent of the choice for a specific calculation procedure, agreement on an update procedure of ADPs and category totals is required when the ADP is used for public policies such as the EPD and PEF (Wardenaar et al. 2012). Assuming that USGS and BGS will continue to publish production data in the upcoming years, a recurring period will need to be defined after which ADPs and category totals will be updated to the latest production data. An obvious option for this is to calculate new ADPs and category totals every 5 years, as this would follow update cycle for other impact categories such as the update of GWPs by the Intergovernmental (IPCC, 2018).

\subsection{Consistency}

For a consistent calculation of normalized indicator results for ADP-based abiotic resource depletion, it is crucial that the ADPs and category total are based on the same characterization model, use the same input data for $P$ and $R$, and represent the same spatial scale (i.e., spatial scales of characterization 
Table 3 ADPs ( $\mathrm{kg} \mathrm{Sb}$ eq $/ \mathrm{kg}$ ) for the most recent year (2015) and different versions of averaged and cumulative ADPs

\begin{tabular}{|c|c|c|c|c|c|}
\hline Element & ADP 1999 & ADP 2015 & $\begin{array}{l}\text { Moving average } \\
\text { ADP } 2015 \\
\text { ( } 5 \text { years })\end{array}$ & $\begin{array}{l}\text { Moving average } \\
\text { ADP } 2015 \\
\text { (20 years) }\end{array}$ & $\begin{array}{l}\text { Cumulative ADP } \\
1970-2015 \\
\text { (46 years) }\end{array}$ \\
\hline Aluminum & $1.1 \mathrm{E}-09$ & $4.2 \mathrm{E}-08$ & $3.7 \mathrm{E}-08$ & $3.7 \mathrm{E}-08$ & $2.5 \mathrm{E}-08$ \\
\hline Antimony & $1.0 \mathrm{E}+00$ & $1.0 \mathrm{E}+00$ & $1.0 \mathrm{E}+00$ & $1.0 \mathrm{E}+00$ & $1.0 \mathrm{E}+00$ \\
\hline Arsenic & $3.0 \mathrm{E}-03$ & $1.3 \mathrm{E}-03$ & $1.2 \mathrm{E}-03$ & $1.8 \mathrm{E}-03$ & $2.4 \mathrm{E}-03$ \\
\hline Barium & $6.0 \mathrm{E}-06$ & $1.2 \mathrm{E}-05$ & $1.2 \mathrm{E}-05$ & $1.2 \mathrm{E}-05$ & $1.4 \mathrm{E}-05$ \\
\hline Beryllium & $1.3 \mathrm{E}-05$ & $6.0 \mathrm{E}-05$ & $5.2 \mathrm{E}-05$ & $5.7 \mathrm{E}-05$ & $7.9 \mathrm{E}-05$ \\
\hline Bismuth & $4.1 \mathrm{E}-02$ & $5.9 \mathrm{E}-01$ & $3.9 \mathrm{E}-01$ & $2.7 \mathrm{E}-01$ & $3.0 \mathrm{E}-01$ \\
\hline Boron & $4.3 \mathrm{E}-03$ & $9.8 \mathrm{E}-03$ & $7.1 \mathrm{E}-03$ & $5.2 \mathrm{E}-03$ & $5.0 \mathrm{E}-03$ \\
\hline Bromine & $4.4 \mathrm{E}-03$ & $1.5 \mathrm{E}-03$ & $1.4 \mathrm{E}-03$ & $1.5 \mathrm{E}-03$ & $1.5 \mathrm{E}-03$ \\
\hline Cadmium & $1.6 \mathrm{E}-01$ & $3.2 \mathrm{E}+00$ & $2.7 \mathrm{E}+00$ & $2.7 \mathrm{E}+00$ & $3.6 \mathrm{E}+00$ \\
\hline Calcium & & $5.4 \mathrm{E}-07$ & $4.6 \mathrm{E}-07$ & $3.4 \mathrm{E}-07$ & $3.6 \mathrm{E}-07$ \\
\hline Carbon & & $3.8 \mathrm{E}-05$ & $3.3 \mathrm{E}-05$ & $2.8 \mathrm{E}-05$ & $3.2 \mathrm{E}-05$ \\
\hline Cerium & & $1.5 \mathrm{E}-05$ & $1.3 \mathrm{E}-05$ & $1.4 \mathrm{E}-05$ & $2.0 \mathrm{E}-05$ \\
\hline Cesium & & $2.8 \mathrm{E}-03$ & $2.2 \mathrm{E}-03$ & $2.1 \mathrm{E}-03$ & $1.9 \mathrm{E}-03$ \\
\hline Chlorine & $2.7 \mathrm{E}-05$ & $5.3 \mathrm{E}-06$ & $4.6 \mathrm{E}-06$ & $4.4 \mathrm{E}-06$ & $5.3 \mathrm{E}-06$ \\
\hline Chromium & $4.4 \mathrm{E}-04$ & $1.2 \mathrm{E}-03$ & $1.1 \mathrm{E}-03$ & $7.7 \mathrm{E}-04$ & $7.9 \mathrm{E}-04$ \\
\hline Cobalt & $1.6 \mathrm{E}-05$ & $4.7 \mathrm{E}-04$ & $3.8 \mathrm{E}-04$ & $2.5 \mathrm{E}-04$ & $2.5 \mathrm{E}-04$ \\
\hline Copper & $1.4 \mathrm{E}-03$ & $2.7 \mathrm{E}-02$ & $2.2 \mathrm{E}-02$ & $2.0 \mathrm{E}-02$ & $2.1 \mathrm{E}-02$ \\
\hline Dysprosium & & $7.0 \mathrm{E}-05$ & $5.4 \mathrm{E}-05$ & $5.4 \mathrm{E}-05$ & $4.9 \mathrm{E}-05$ \\
\hline Erbium & & $1.1 \mathrm{E}-04$ & $8.4 \mathrm{E}-05$ & $8.3 \mathrm{E}-05$ & $7.5 \mathrm{E}-05$ \\
\hline Europium & & $4.2 \mathrm{E}-04$ & $3.2 \mathrm{E}-04$ & $3.2 \mathrm{E}-04$ & $2.9 \mathrm{E}-04$ \\
\hline Fluorine & & $1.3 \mathrm{E}-05$ & $1.2 \mathrm{E}-05$ & $9.9 \mathrm{E}-06$ & $1.3 \mathrm{E}-05$ \\
\hline Gadolinium & & $9.2 \mathrm{E}-05$ & $7.1 \mathrm{E}-05$ & $7.1 \mathrm{E}-05$ & $6.4 \mathrm{E}-05$ \\
\hline Gallium & $1.5 \mathrm{E}-07$ & $1.7 \mathrm{E}-06$ & $1.3 \mathrm{E}-06$ & $5.4 \mathrm{E}-07$ & $4.2 \mathrm{E}-07$ \\
\hline Germanium & $6.5 \mathrm{E}-07$ & $9.2 \mathrm{E}-05$ & $7.6 \mathrm{E}-05$ & $5.2 \mathrm{E}-05$ & $7.0 \mathrm{E}-05$ \\
\hline Gold & $5.2 \mathrm{E}+01$ & $1.5 \mathrm{E}+03$ & $1.3 \mathrm{E}+03$ & $1.2 \mathrm{E}+03$ & $1.4 \mathrm{E}+03$ \\
\hline Hafnium & & $2.9 \mathrm{E}-06$ & $2.5 \mathrm{E}-06$ & $2.8 \mathrm{E}-06$ & $3.9 \mathrm{E}-06$ \\
\hline Holmium & & $1.9 \mathrm{E}-04$ & $1.5 \mathrm{E}-04$ & $1.5 \mathrm{E}-04$ & $1.3 \mathrm{E}-04$ \\
\hline Hydrogen & & $8.5 \mathrm{E}-09$ & $7.2 \mathrm{E}-09$ & $5.5 \mathrm{E}-09$ & $5.8 \mathrm{E}-09$ \\
\hline Indium & $6.9 \mathrm{E}-03$ & $2.3 \mathrm{E}-01$ & $2.0 \mathrm{E}-01$ & $1.4 \mathrm{E}-01$ & $1.1 \mathrm{E}-01$ \\
\hline Iodine & $2.5 \mathrm{E}-02$ & $1.7 \mathrm{E}-02$ & $1.4 \mathrm{E}-02$ & $1.3 \mathrm{E}-02$ & $1.3 \mathrm{E}-02$ \\
\hline Iridium & & $1.4 \mathrm{E}+02$ & $1.2 \mathrm{E}+02$ & $1.4 \mathrm{E}+02$ & $1.9 \mathrm{E}+02$ \\
\hline Iron & $5.2 \mathrm{E}-08$ & $1.1 \mathrm{E}-06$ & $9.5 \mathrm{E}-07$ & $7.1 \mathrm{E}-07$ & $6.9 \mathrm{E}-07$ \\
\hline Lanthanum & & $3.7 \mathrm{E}-05$ & $2.9 \mathrm{E}-05$ & $2.9 \mathrm{E}-05$ & $2.6 \mathrm{E}-05$ \\
\hline Lead & $6.3 \mathrm{E}-03$ & $1.9 \mathrm{E}-02$ & $1.7 \mathrm{E}-02$ & $1.4 \mathrm{E}-02$ & $1.9 \mathrm{E}-02$ \\
\hline Lithium & $1.1 \mathrm{E}-05$ & $5.2 \mathrm{E}-05$ & $4.5 \mathrm{E}-05$ & $2.9 \mathrm{E}-05$ & $2.6 \mathrm{E}-05$ \\
\hline Lutetium & & $1.0 \mathrm{E}-03$ & $7.8 \mathrm{E}-04$ & $7.7 \mathrm{E}-04$ & $7.0 \mathrm{E}-04$ \\
\hline Magnesium & $2.0 \mathrm{E}-09$ & $2.8 \mathrm{E}-07$ & $2.5 \mathrm{E}-07$ & $2.5 \mathrm{E}-07$ & $1.7 \mathrm{E}-07$ \\
\hline Manganese & $2.5 \mathrm{E}-06$ & $3.3 \mathrm{E}-05$ & $2.7 \mathrm{E}-05$ & $2.0 \mathrm{E}-05$ & $2.5 \mathrm{E}-05$ \\
\hline Mercury & $9.2 \mathrm{E}-02$ & $1.5 \mathrm{E}+00$ & $9.7 \mathrm{E}-01$ & $8.1 \mathrm{E}-01$ & $2.7 \mathrm{E}+00$ \\
\hline Molybdenum & $1.8 \mathrm{E}-02$ & $2.2 \mathrm{E}-01$ & $2.1 \mathrm{E}-01$ & $1.6 \mathrm{E}-01$ & $1.7 \mathrm{E}-01$ \\
\hline Neodymium & & $3.1 \mathrm{E}-05$ & $2.4 \mathrm{E}-05$ & $2.4 \mathrm{E}-05$ & $2.2 \mathrm{E}-05$ \\
\hline Nickel & $6.5 \mathrm{E}-05$ & $1.2 \mathrm{E}-03$ & $1.1 \mathrm{E}-03$ & $7.9 \mathrm{E}-04$ & $8.1 \mathrm{E}-04$ \\
\hline Niobium & $1.9 \mathrm{E}-05$ & $5.0 \mathrm{E}-04$ & $4.2 \mathrm{E}-04$ & $3.3 \mathrm{E}-04$ & $2.9 \mathrm{E}-04$ \\
\hline Nitrogen & & $5.0 \mathrm{E}-05$ & $4.3 \mathrm{E}-05$ & $4.1 \mathrm{E}-05$ & $4.6 \mathrm{E}-05$ \\
\hline Osmium & & $5.4 \mathrm{E}+01$ & $4.7 \mathrm{E}+01$ & $5.1 \mathrm{E}+01$ & $7.3 \mathrm{E}+01$ \\
\hline Oxygen & & $3.2 \mathrm{E}-09$ & $2.8 \mathrm{E}-09$ & $2.8 \mathrm{E}-09$ & $2.0 \mathrm{E}-09$ \\
\hline Palladium & $5.7 \mathrm{E}-01$ & $9.8 \mathrm{E}+02$ & $8.5 \mathrm{E}+02$ & $9.9 \mathrm{E}+02$ & $9.7 \mathrm{E}+02$ \\
\hline Phosphorus & $5.5 \mathrm{E}-06$ & $8.6 \mathrm{E}-05$ & $7.0 \mathrm{E}-05$ & $5.6 \mathrm{E}-05$ & $7.1 \mathrm{E}-05$ \\
\hline
\end{tabular}


Table 3 (continued)

\begin{tabular}{|c|c|c|c|c|c|}
\hline Element & ADP 1999 & ADP 2015 & $\begin{array}{l}\text { Moving average } \\
\text { ADP } 2015 \\
(5 \text { years })\end{array}$ & $\begin{array}{l}\text { Moving average } \\
\text { ADP } 2015 \\
\text { ( } 20 \text { years) }\end{array}$ & $\begin{array}{l}\text { Cumulative ADP } \\
1970-2015 \\
\text { (46 years) }\end{array}$ \\
\hline Platinum & $2.2 \mathrm{E}+00$ & $1.0 \mathrm{E}+03$ & $8.2 \mathrm{E}+02$ & $9.0 \mathrm{E}+02$ & $9.7 \mathrm{E}+02$ \\
\hline Potassium & $1.6 \mathrm{E}-08$ & $1.9 \mathrm{E}-07$ & $1.7 \mathrm{E}-07$ & $1.7 \mathrm{E}-07$ & $1.3 \mathrm{E}-07$ \\
\hline Praseodymium & & $1.4 \mathrm{E}-04$ & $1.1 \mathrm{E}-04$ & $1.1 \mathrm{E}-04$ & $9.7 \mathrm{E}-05$ \\
\hline Rhenium & $6.0 \mathrm{E}-01$ & $1.4 \mathrm{E}+03$ & $1.2 \mathrm{E}+03$ & $1.1 \mathrm{E}+03$ & $1.0 \mathrm{E}+03$ \\
\hline Rhodium & & $2.1 \mathrm{E}-03$ & $1.8 \mathrm{E}-03$ & $2.0 \mathrm{E}-03$ & $2.8 \mathrm{E}-03$ \\
\hline Ruthenium & & $2.7 \mathrm{E}+02$ & $2.4 \mathrm{E}+02$ & $2.6 \mathrm{E}+02$ & $3.7 \mathrm{E}+02$ \\
\hline Samarium & & $1.1 \mathrm{E}-04$ & $8.6 \mathrm{E}-05$ & $8.5 \mathrm{E}-05$ & $7.7 \mathrm{E}-05$ \\
\hline Scandium & & $5.6 \mathrm{E}-08$ & $4.9 \mathrm{E}-08$ & $5.4 \mathrm{E}-08$ & $7.6 \mathrm{E}-08$ \\
\hline Selenium & $1.9 \mathrm{E}-01$ & $3.1 \mathrm{E}-01$ & $2.7 \mathrm{E}-01$ & $2.5 \mathrm{E}-01$ & $3.1 \mathrm{E}-01$ \\
\hline Silicon & $1.4 \mathrm{E}-11$ & $1.3 \mathrm{E}-09$ & $1.1 \mathrm{E}-09$ & $8.4 \mathrm{E}-10$ & $8.2 \mathrm{E}-10$ \\
\hline Silver & $1.2 \mathrm{E}+00$ & $1.0 \mathrm{E}+01$ & $8.8 \mathrm{E}+00$ & $7.8 \mathrm{E}+00$ & $8.6 \mathrm{E}+00$ \\
\hline Sodium & $5.5 \mathrm{E}-08$ & $1.9 \mathrm{E}-07$ & $1.6 \mathrm{E}-07$ & $1.5 \mathrm{E}-07$ & $1.7 \mathrm{E}-07$ \\
\hline Strontium & $7.1 \mathrm{E}-07$ & $1.7 \mathrm{E}-06$ & $1.5 \mathrm{E}-06$ & $1.8 \mathrm{E}-06$ & $1.7 \mathrm{E}-06$ \\
\hline Sulfur & $1.9 \mathrm{E}-04$ & $1.8 \mathrm{E}-04$ & $1.5 \mathrm{E}-04$ & $1.3 \mathrm{E}-04$ & $1.6 \mathrm{E}-04$ \\
\hline Tantalum & $4.1 \mathrm{E}-05$ & $1.6 \mathrm{E}-03$ & $1.4 \mathrm{E}-03$ & $1.4 \mathrm{E}-03$ & $1.3 \mathrm{E}-03$ \\
\hline Tellurium & $4.1 \mathrm{E}+01$ & $1.1 \mathrm{E}+02$ & $9.3 \mathrm{E}+01$ & $1.1 \mathrm{E}+02$ & $1.7 \mathrm{E}+02$ \\
\hline Terbium & & $3.8 \mathrm{E}-04$ & $3.0 \mathrm{E}-04$ & $2.9 \mathrm{E}-04$ & $2.7 \mathrm{E}-04$ \\
\hline Thallium & $2.4 \mathrm{E}-05$ & $1.4 \mathrm{E}-05$ & $1.2 \mathrm{E}-05$ & $1.6 \mathrm{E}-05$ & $1.9 \mathrm{E}-05$ \\
\hline Thulium & & $7.2 \mathrm{E}-04$ & $5.6 \mathrm{E}-04$ & $5.5 \mathrm{E}-04$ & $5.0 \mathrm{E}-04$ \\
\hline Tin & $1.6 \mathrm{E}-02$ & $7.4 \mathrm{E}-02$ & $6.0 \mathrm{E}-02$ & $6.4 \mathrm{E}-02$ & $8.1 \mathrm{E}-02$ \\
\hline Titanium & $2.8 \mathrm{E}-08$ & $4.0 \mathrm{E}-07$ & $3.7 \mathrm{E}-07$ & $3.5 \mathrm{E}-07$ & $3.8 \mathrm{E}-07$ \\
\hline Tungsten & $4.5 \mathrm{E}-03$ & $2.8 \mathrm{E}-02$ & $2.3 \mathrm{E}-02$ & $1.7 \mathrm{E}-02$ & $2.1 \mathrm{E}-02$ \\
\hline Uranium $^{1}$ & & $9.4 \mathrm{E}-03$ & $7.8 \mathrm{E}-03$ & $6.3 \mathrm{E}-03$ & $7.8 \mathrm{E}-03$ \\
\hline Vanadium & $7.7 \mathrm{E}-07$ & $9.3 \mathrm{E}-06$ & $8.1 \mathrm{E}-06$ & $6.3 \mathrm{E}-06$ & $6.6 \mathrm{E}-06$ \\
\hline Ytterbium & & $1.5 \mathrm{E}-04$ & $1.1 \mathrm{E}-04$ & $1.1 \mathrm{E}-04$ & $1.0 \mathrm{E}-04$ \\
\hline Yttrium & $5.7 \mathrm{E}-07$ & $1.6 \mathrm{E}-05$ & $1.2 \mathrm{E}-05$ & $1.2 \mathrm{E}-05$ & $1.1 \mathrm{E}-05$ \\
\hline Zinc & $5.4 \mathrm{E}-04$ & $3.2 \mathrm{E}-03$ & $2.8 \mathrm{E}-03$ & $2.4 \mathrm{E}-03$ & $2.8 \mathrm{E}-03$ \\
\hline Zirconium & $5.4 \mathrm{E}-06$ & $3.4 \mathrm{E}-05$ & $2.8 \mathrm{E}-05$ & $2.3 \mathrm{E}-05$ & $2.6 \mathrm{E}-05$ \\
\hline
\end{tabular}

av, average; cum, cumulative

${ }^{1}$ In the PEF, uranium is included in the impact category Resource Depletion Fossil Fuels (or better Energy Carriers). However, in the updated set of characterization factors originally compiled by van Oers et al. (2002), uranium is part of the impact category Resource Depletion Elements. Uranium is used for many different applications, not only for energy supply

model and normalization reference area), and that the category total is based on the same complete set of elements as for which ADPs have been derived. ${ }^{5}$

\footnotetext{
${ }^{5}$ In order to prevent consistency problems when implementing the characterization factors and category total developed in LCA software-database combinations, it is recommended to implement a category total as a fixed number rather than as a set of world annual extractions that still have to be multiplied with their corresponding characterization factors. The latter can easily result in inconsistencies due to the fact that not all elements, for which characterization factors and a category total have been calculated in this study, are covered by databases implemented in the LCA software. Note that in this set-up, each characterization method will need a specific category total as a category total is only valid for one specific characterization methods. Note also that if characterization methods are updated, the related category total should also be updated.
}

Considering the reference period, the question is what to adopt as "world annual extraction" for calculating the category total. Should the same choice be made for this "world annual extraction" $\left(M_{i}\right)$ as made for the ADP (cumulative production over a number of years, $\left.P_{i}\right)$ ? Our answer would be "no". We argue that in line with global warming and other impact categories, the production data for the most recent and completely documented reference year should be adopted, for all impact categories. The aim of normalization is to compare characterization results with the same reference information, e.g., characterization results for the world for a given year. Preferably, the same reference year (and region) should be adopted for all "world annual emission/extraction" data sets for all impact categories, which is also how these data have 
been collected so far (van Oers and Huppes 2001; Wegener Sleeswijk et al. 2008; Sala et al. 2015). Depending on the reference year adopted for other impact categories, the proper reference year for the "world annual extraction" for the ADP should be selected from the accompanying spreadsheet ESM1, e.g., 2010. Of course, we could also take the cumulative production over a number of years as reference but then we should take a similar reference for other impact categories (e.g., cumulative emissions over the same period). That would require cumulative emission data, which may not always be available.

Considering the reference area, we want to briefly point at an inconsistency in the use of the reference area as currently adopted in the PEF. In the current PEF, ADPs based on the USGS reserve base are combined with European ("domestic") annual extractions for 2010 published by Sala et al. (2015). Compared with the category totals developed in this article, Sala et al. (2015) adopted another reference area for normalization (EU 27 instead of the world), use the USGS reserve base instead of crustal content for the $R$, and moved uranium from minerals to he fossil energy category while changing the name of this category to "energy carriers". This EU 27 normalization is problematic in several ways: the $P$ in

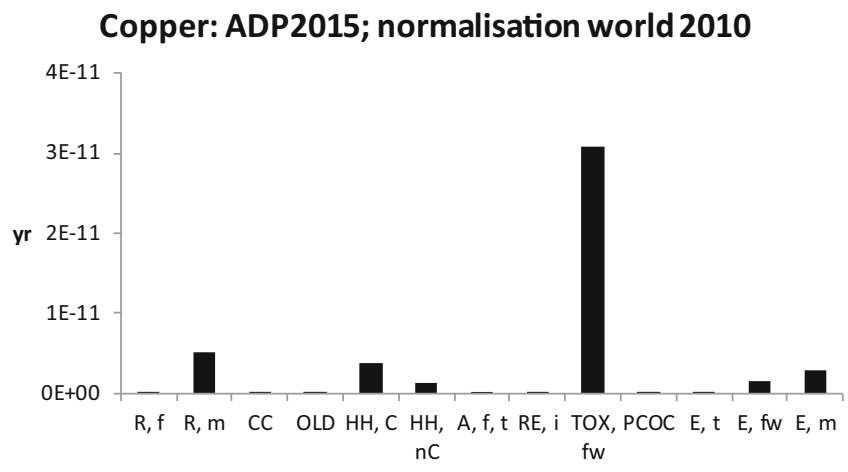

Copper: ADP2015; normalisation EU27 2010

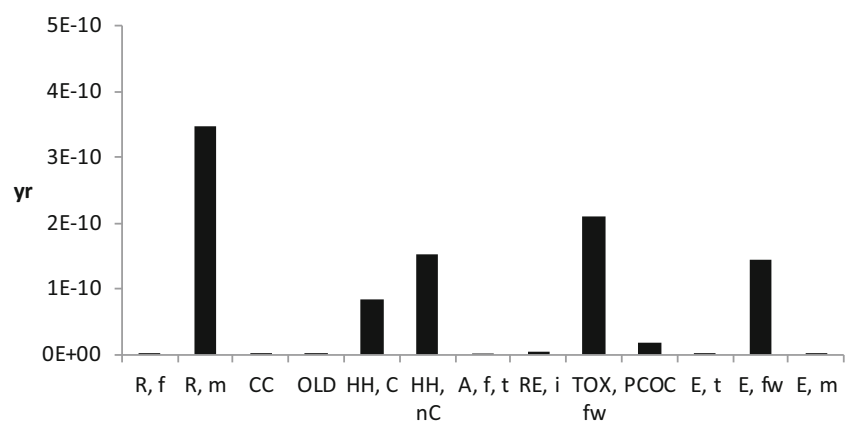

Fig. 5 Normalized indicator results adopting two different normalization reference areas (the EU27 as normalization reference area and the world) for 2010 for the cradle-to-gate production of $1 \mathrm{~kg}$ of copper and $1 \mathrm{kWh}$ of electricity Dutch mix, adopting the 'ILCD 1.0.8 2016 midpoint' methods as implemented in ecoinvent $\mathrm{v} 3$ except for the ADP, which is taken from this study for the year 2015 (ADP2015). ( $R, f=$ resources, fossil energy carriers; $R, m=$ resources, minerals; $C C=$ climate change; $O L D=$ ozone the ADP reflects world production and is compared with an $M$ in normalization that reflects EU 27 production. This results in an inconsistent calculation of normalized indicator results since not all elements, for which there are ADPs, are mined within the EU 27 but rather imported (either as resource or as processed resource in materials and products). Altogether, this means that inventory data on metal, mineral, and fossil resources appear to be available for only 34 out of 74 elementary flows for which there is an ADP (Sala et al. 2015). Similar problems will also affect normalization results for other impact categories. Using crustal content data for $R$, considering uranium as mineral and not as energy carriers, and adopting 2010 as reference year for normalization, Fig. 5 shows the influence of adopting the EU 27 as the normalization reference area (covering 34 elements) instead of the world (covering 74 elements) for the cases of $1 \mathrm{~kg}$ copper and $1 \mathrm{kWh}$ of electricity Dutch mix, adopting the "ILCD 1.0.8 2016 midpoint" methods as implemented in ecoinvent v3 except for the ADP, which is taken from this study for the year 2015 $\left(\mathrm{ADP}_{2015}\right)$. We see some remarkable differences between the global and EU 27 results, for the mineral resource, toxicity-related, and the freshwater eutrophication

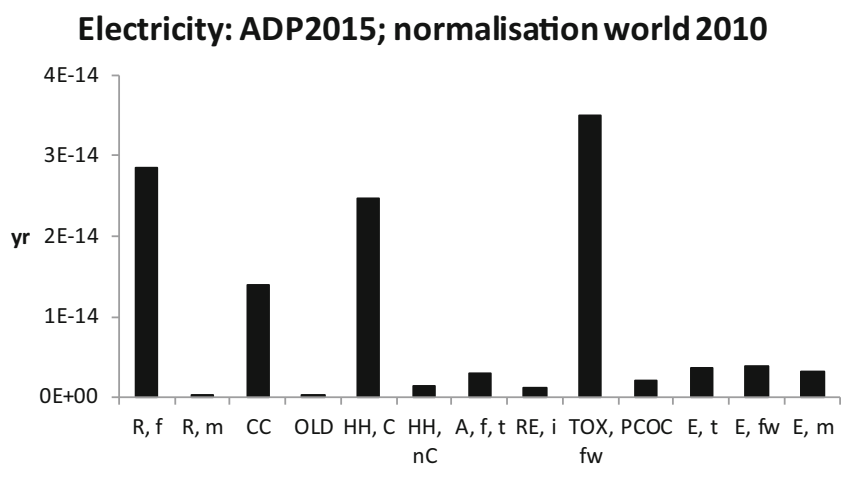

Electricity: ADP2015; normalisation EU27 2010

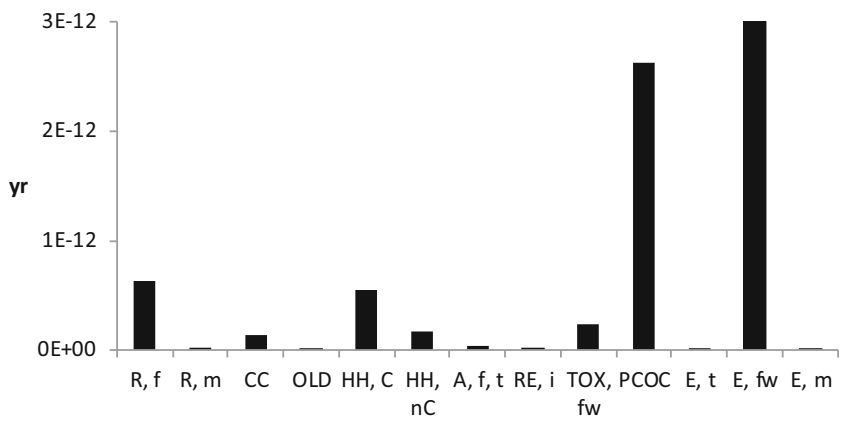

layer depletion; $H H, C=$ human health, carcinogenic effects; $H H, n C=$ human health, non-carcinogenic effects; $A, f, t=$ freshwater and terrestrial acidification; $R E, i=$ respiratory effects, inorganics; $T O X, f w=$ freshwater ecotoxicity; $P C O C=$ photochemical ozone creation; $E, t=$ terrestrial eutrophication; $E, f w=$ freshwater eutrophication; $E, m=$ marine eutrophication) 
categories. All of these differences are related to the difference in the reference area for normalization. ${ }^{6}$

In general, the following reasoning can be useful for analyzing the validity and reliability of normalized indicator results. Assuming representation by perfect data and full coverage of all possible elementary flows, in general, one expects that a typical functional unit should show normalized indicator results for the different impact categories in the same order of magnitude. In appendix A (ESM), a mathematical proof is given for this statement. However, as perfect data and coverage and the "typical functional unit" do not exist, practice may turn out differently. Specific products may show (normalized) indicator results for abiotic resource depletion (or any other impact category) that deviates from the order of magnitude from the other impact categories. For example, the normalized indicator results for ADP-based abiotic resource depletion for $1 \mathrm{~kg}$ of copper are up to a factor or 3 higher in comparison with other impact categories. This is largely explained by the fact that resources play a dominant role in the inventory result of $1 \mathrm{~kg}$ of copper production and by copper's relatively high ADP, which is due to its relatively low crustal content combined with relatively high production. Note that the normalized characterized scores only reflect the relative ranking of resources within the impact category, without any indication of the seriousness of the problem compared with other impact categories (which is weighting). Although copper's ADP is relatively high due to how the factor is calculated, the USGS estimates copper reserves amount to 790 million tonnes, and copper resources are currently estimated over 5000 million tonnes (USGS 2018). Thus, the result should be interpreted carefully by the study user.

However, if normalized indicator results for a certain impact category are by 1 or more orders of magnitude higher than for other categories, this potentially points at consistency and/or coverage problems as explained above and as well-known for the toxicity-related impact categories (Heijungs et al. 2007; Prado et al. 2016).

\section{Conclusions}

The aim of this project was to update the data $(R$ and $P)$ behind the ADP for elements, to revisit its calculation procedure to better deal with the time dependency of $P$ data, and to develop a

\footnotetext{
${ }^{6}$ For example, there is no mining of gold in EU 27. As a consequence, the category total for the EU 27 will lack the contribution of gold. However, an inventory of a case study might very well include the extraction of gold somewhere outside the EU 27. Then, the characterized category indicator result (based on ADPs using global production data and including gold, for example) is divided by the EU 27 category total (based on EU27 production data only and excluding gold, for example) to calculate the normalized category indicator result. Because gold is lacking in the category total, this will lead to an overestimation of the normalized score. Similar mechanisms hold for toxicity and eutrophication.
}

proposal for a more robust updating procedure of the data behind the ADP and its category total. We conclude that the update of data and the revision of calculation procedures of ADPs and category totals have resulted in an improved, up-to-date, and more complete set of ADPs and related category total.

The crustal content data that are the basis of the ultimate reserve estimates $(R)$ in the ADP have been updated by using the crustal content data as reported by Rudnick and Gao (2014). These data are considered the standard for average concentration data on elements in the continental crust within the geoscience community.

Production data of USGS and BGS have been reviewed and combined to make the set of production data as complete as possible, thus improving the coverage of elements by ADPs. The production data of elements now also takes into account some of the non-dedicated extraction of elements by the extraction of minerals that are not used for the production of metals and elements but are used as mineral sec. Pre-existing concerns about the robustness and correct curating of such data within the USGS and BGS have not been resolved by this study and therefore remain the subject of ongoing research (MinFuture, 2018).

Production of elements fluctuates considerably over time; in this update, we have calculated ADPs adopting several calculation procedures including averaging over a number of years and aggregating production data over a number of years. We conclude that the cumulative ADP overall years is most in line with the intent of the original ADP method. We recommend to only use up-to-date (cumulative) ADPs. For the calculation of the category totals, we recommend to use noncumulative category totals based on the production in a recent year (less than 5 years old).

The analyses performed in this study have shown that the variability of production data, and then in particular production of gold dominates the category totals, and that reserve data are less important (see ESM 2). This is a common feature of the current state-of-the-art of normalization for other impact categories as well.

Although the production data for the reference element, antimony, change over time, the effects are not much larger than when another reference element would be chosen. Furthermore, the choice of the reference element will not affect the relative scores in a comparative analysis or the contribution by different resources within one product design change.

Last but not least, it is crucial for a consistent calculation of normalized indicator results for ADP-based abiotic resource depletion that the ADPs and category total are based on the same characterization model, use the same ADPs (i.e., $\mathrm{ADP}_{\text {cum }}$ ), and use a reference area and reference time (i.e., calendar year) that is consistent with normalization area and time for other impact categories. Moreover, the category total should be based on the same complete set of elements as for which ADPs have been derived. 
Funding information The authors thank the International Council on Mining and Metals (ICMM) for funding this research.

Open Access This article is distributed under the terms of the Creative Commons Attribution 4.0 International License (http:// creativecommons.org/licenses/by/4.0/), which permits unrestricted use, distribution, and reproduction in any medium, provided you give appropriate credit to the original author(s) and the source, provide a link to the Creative Commons license, and indicate if changes were made.

\section{References}

Adibi N, Lafhaj Z, Payet J (2018). New resource assessment characterization factors for rare earth elements: applied in $\mathrm{NdFeB}$ permanent magnet case study. Int J Life Cycle Assess. (FirstOnLine), https:// doi.org/10.1007/s11367-018-1489-x.

British Geological Survey (2018) World mineral statistics data. http:// www.bgs.ac.uk/mineralsuk/statistics/wms.cfc?method= searchWMS. Accessed 15 Nov 2018

Clarke FW, Washington HS (1924) The composition of the Earth's crust; USGS professional paper 127. Washington, DC

CML-IE CML-IA Characterisation Factors. In: C. Characterisation Factors. https://www.universiteitleiden.nl/en/research/researchoutput/science/cml-ia-characterisation-factors. Accessed 23 Nov 2018

Deloitte Sustainability, British Geological Survey, Bureau de Recherches Géologiques et Minières, Research NO for AS (2017) Study on the review of the list of Critical Raw Materials - Critical Raw Materials Factsheets. Brussels

Drielsma JA, Russell-Vaccari AJ, Drnek T, Brady T, Weihed P, Mistry M, Simbor LP (2016) Mineral resources in life cycle impact assessment - defining the path forward. Int J Life Cycle Assess 21:85-105

EPD International (2017) General Programme Instructions for the International EPD® System - Version 3.0

European Commisison (2017) PEFCR Guidance document, - guidance for the development of product environmental footprint category rules (PEFCRs), Version 6.3, December 2017. Brussels

European Commission (2013) On the use of common methods to measure and communicate the life cycle environmental performance of products and organisations. Off J Eur Union 4:210

Guinée JB, Heijungs R (1995) A proposal for the definition of resource equivalency factors for use in product life-cycle assessment. Environ Toxicol Chem 14:917-925

Guinée JB, Gorrée M, Heijungs R et al (2002) Handbook on life cycle assessment: operational guide to the ISO standards, series: Ec. Springer, Dordrecht

Harte J (1988) Consider a spherical cow - a course in environmental problem solving. University Science Books, Mill Valley

Hauschild MZ, Goedkoop M, Guinée J, Heijungs R, Huijbregts M, Jolliet O, Margni M, de Schryver A, Humbert S, Laurent A, Sala S, Pant R (2013) Identifying best existing practice for characterization modeling in life cycle impact assessment. Int J Life Cycle Assess 18:683697
Heijungs R, Guinée J, Kleijn R, Rovers V (2007) Bias in normalization: causes, consequences, detection and remedies. Int $\mathrm{J}$ Life Cycle Assess 12:211-216

IPCC Reports. http://www.ipcc.ch/publications_and_data/publications_ and_data_reports.shtml. Accessed 23 Nov 2018

Lide DR (1990) CRC handbook of chemistry and physics, 71st edn. CRC Press, Boston

MinFuture Global material flows and demand-supply forecasting for mineral strategies. https://minfuture.eu/. Accessed 23 Nov 2018

Prado V, Wender B, Seager TP (2016) Interpretation of comparative LCAs: external normalization and a method of mutual differences. Int J Life Cycle Assess 22:2018-2029

Rudnick R, Gao S (2014) Composition of the continental crust. In: Holland H, Turekian K (eds) Treatise on geochemistry, 2nd edn. Elsevier, Oxford, pp 1-51

Sala S, Benini L, Mancini L, Pant R (2015) Integrated assessment of environmental impact of Europe in 2010: data sources and extrapolation strategies for calculating normalisation factors. Int $\mathrm{J}$ Life Cycle Assess 20:1568-1585

Schneider L, Berger M, Finkbeiner M (2015) Abiotic resource depletion in LCA - background and update of the anthropogenic stock extended abiotic depletion potential (AADP) model. Int J Life Cycle Assess 20:709-721

Schulze R, Guinée J (2018) Suprim workshop report DELIVERABLE D2.1. Leiden, The Netherlands

Sonderegger T, Dewulf J, Fantke P, de Souza DM, Pfister S, Stoessel F, Verones F, Vieira M, Weidema B, Hellweg S (2017) Towards harmonizing natural resources as an area of protection in life cycle impact assessment. Int J Life Cycle Assess 22:1912-1927

US Geological Survey (2018) Minerals information. https://minerals. usgs.gov/minerals/pubs/historical-statistics/. Accessed 15 Nov 2018

van Oers L, Guinée J (2016) The abiotic depletion potential: background, updates, and future. Resources 5:16

van Oers L, Huppes G (2001) LCA normalisation factors for the Netherlands, Western Europe and the world. Int J Life Cycle Assess 6:256

Oers L van, Koning A de, Guinée JB, Huppes G (2002) Abiotic resource depletion in LCA - improving characterisation factors fro abiotic depletion as recommended in the new Dutch LCA Handbook

Wardenaar T, Van Ruijven T, Beltran AM et al (2012) Differences between LCA for analysis and LCA for policy: a case study on the consequences of allocation choices in bio-energy policies. Int J Life Cycle Assess 17:1059-1067

Wegener Sleeswijk A, Van Oers LFCM, Guinée JB et al (2008) Normalisation in product life cycle assessment : an LCA of the global and European economic systems in the year 2000. Sci Total Environ 390:227-240

White WM, Klein EM (2014) Composition of the oceanic crust. In: Holland HD, Turekian KK (eds) Treatise on geochemistry, 2nd edn. Elsevier, Oxford, pp 457-496

Publisher's note Springer Nature remains neutral with regard to jurisdictional claims in published maps and institutional affiliations. 